\title{
Gas phase polymerization of ethylene with a silica- supported metallocene catalyst: influence of temperature on deactivation
}

\author{
Peter Roos, Gerben B. Meier, Job Jan C. Samson, Günter Weickert, \\ K. Roel Westerterp* \\ University of Twente, Faculty of Chemical Engineering, P.O. Box 217, NL-7500 AE, \\ Enschede, The Netherlands
}

(Received: August 27, 1996; revised manuscript of October 1, 1996)

\section{SUMMARY:}

Ethylene was polymerized at 5 bar in a stirred powder bed reactor with silica supported rac- $\mathrm{Me}_{2} \mathrm{Si}[\mathrm{Ind}]_{2} \mathrm{ZrCl}_{2} /$ methylaluminoxane (MAO) at temperatures between $40^{\circ} \mathrm{C}$ and $80^{\circ} \mathrm{C}$ using $\mathrm{NaCl}$ as support bed and triethylaluminium (TEA) as a scavenger for impurities. For this fixed recipe and a given charge of catalyst, the average catalyst activity is reproducible within $10 \%$ for low temperatures. The polymerization rate and the rate of deactivation increase with increasing temperature. The deactivation could be modeled using a first order dependence with respect to the polymerization rate.

\section{Introduction}

In recent years, versatile catalysts based upon methylaluminoxane (MAO) activated metallocenes have been developed ${ }^{1,2)}$. These organometallic complexes are able to polymerize $a$-olefins stereoselectively with high activity and narrow molecular weight distributions ${ }^{3-6)}$. Almost all public research is directed to the development of new metallocenes and conducted in the slurry phase ${ }^{7-10)}$. Tsutsui and Kashiwa have investigated the gas phase polymerization of propylene with a non-supported solid complex catalyst obtained from $\mathrm{Et}[\mathrm{Ind}]_{2} \mathrm{ZrCl}_{2}$ and methylaluminoxane using $\mathrm{NaCl}$ as a disperse medium ${ }^{11)}$. Up to now no data is available in the open literature describing the reproducibility of polymerization rate measurements for gas phase olefin polymerization with supported metallocenes.

In this paper we report on the influence of temperature on the gas phase polymerization of ethylene with silica-supported $\mathrm{Me}_{2} \mathrm{Si}[\mathrm{Ind}]_{2} \mathrm{ZrCl}_{2}$.

\section{Experimental part}

\section{Materials}

Triethylaluminium (TEA) and (dimethylsilylene)bis $\left(\eta^{5}\right.$-inden-1-ylidene)zirconium dichloride or $\mathrm{Me}_{2} \mathrm{Si}[\mathrm{Ind}]_{2} \mathrm{ZrCl}_{2}$ (Witco) were used without further purification. The $\mathrm{Me}_{2} \mathrm{Si}[\mathrm{Ind}]_{2} \mathrm{ZrCl}_{2}$ catalyst has been heterogenized on silica gel $(1 \mathrm{wt} \%)$. The silica (SD3216-30, 10-110 $\mu \mathrm{m}$, average $51 \mu \mathrm{m}$, provided by Witco) has been pretreated with methylaluminoxane (MAO) to a concentration of $25 \mathrm{wt} \% \mathrm{Al}$, giving an $[\mathrm{Al}] /[\mathrm{Zr}]$ mole ratio of 386 . Ethylene 2.8 and argon 5.0 were further purified through BTS (reduced state) and molecular sieves columns. $\mathrm{NaCl}$ was purified by drying it under vacuum at $90^{\circ} \mathrm{C}$. 


\section{Polymerization procedures}

In a $1 \mathrm{~L}$ glass autoclave equipped with a helical stirrer, $50 \mathrm{~g}$ of $\mathrm{NaCl}$ is placed as a support bed. The system is vacuum dried at the polymerization temperature and flushed with argon several times. $0.5 \mathrm{~mL}$ of the scavenger (TEA) is injected with argon. After that, the system is flushed with ethylene several times. Subsequently, approximately $0.2 \mathrm{~g}$ of catalyst is injected with argon. Immediately after the injection the reactor is flushed with ethylene to remove the argon. Polymerization is carried out at 5 bar for $200 \mathrm{~min}$. The product is washed with water to remove the salt followed by filtration. The obtained product is vacuum dried for $24 \mathrm{~h}$ at $70^{\circ} \mathrm{C}$.

Gas purities of ethylene and argon were investigated by depressurising the reactor to 1.5 bar followed by refilling with new ethylene to 5 bar during the experiment and by flushing with argon to stop the experiment for $18 \mathrm{~h}$ followed by flushing with ethylene to restart the experiment. None of these procedures influenced the polymerization activity significantly. Therefore deactivation by impurities in the monomer can be excluded ${ }^{12}$.

\section{Results}

Tab. 1 shows the results of the polymerization experiments. Fig. 1 shows the polymerization rate profiles of the experiments listed in Tab. 1. Flushing the reactor with ethylene was carried out within 2 min after the catalyst injection, with the exception of the experiments 120396,130396 and 140396 where the first 25 min couldn't be measured due to the long flushing period.

Tab. 1. Results of ethylene polymerization experiments with $\mathrm{Me}_{2} \mathrm{Si}[\mathrm{Ind}]_{2} \mathrm{ZrCl}_{2}$ as catalyst

\begin{tabular}{lllll}
\hline Exp. no. & $\begin{array}{l}\text { Temp. } \\
\text { in }{ }^{\circ} \mathrm{C}\end{array}$ & $\begin{array}{l}\text { Yield } \\
\text { in } \mathrm{g}\end{array}$ & $\begin{array}{l}\text { Initial } \\
\text { activity }^{\mathrm{a}, \mathrm{b})} \\
\text { in } \mathrm{kg} /(\mathrm{g} / \mathrm{h})\end{array}$ & $\begin{array}{l}\text { Average } \\
\text { activity } \\
\text { in } \mathrm{kg} /(\mathrm{g} / \mathrm{h})\end{array}$ \\
\hline 120396 & 40 & 9.6 & 1.7 & 1.3 \\
220396 & 40 & 10.9 & 1.8 & 1.4 \\
250396 & 50 & 19.6 & 3.5 & 2.7 \\
180396 & 60 & 27.1 & 4.7 & 3.9 \\
130396 & 60 & 25.1 & 4.8 & 3.6 \\
210396 & 70 & 40.5 & 6.7 & 4.9 \\
140396 & 80 & 53.5 & 9.6 & 7.8 \\
200396 & 80 & 38.9 & 7.9 & 5.2
\end{tabular}

a) Average and initial activity in $\mathrm{kg}$ polyethylene per gram metallocene per hour.

b) Initial activity has been extrapolated from the experimental data.

The irregular behavior of the rate profiles in the first $30 \mathrm{~min}$ (especially for the higher temperatures) were caused by the temperature control. Temperature control by cooling a particle/gas system through the relatively thick glass wall is slow. Visual inspection of the product indicated that particle agglomeration and break-up could also contribute to the fluctuations in temperature and activity at the higher temperatures. 


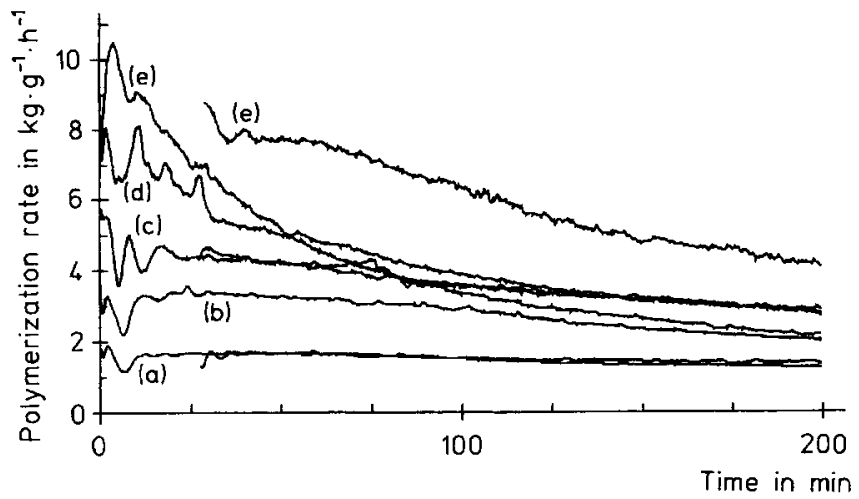

Fig. 1. Ethylene polymerization rate profiles at different temperatures with $\mathrm{Me}_{2} \mathrm{Si}[\mathrm{Ind}]_{2} \mathrm{ZrCl}_{2}$ as catalyst; (a) $40^{\circ} \mathrm{C}+$ duplo, (b) $50^{\circ} \mathrm{C}$, (c) $60^{\circ} \mathrm{C}+$ duplo, (d) $70^{\circ} \mathrm{C}$, (e) $80^{\circ} \mathrm{C}+$ duplo

It can be concluded that the reproducibility of the average activity is rather good (within $10 \%$ ) with the exception of the experiments at the higher temperatures. The spread in deactivation rate at $80^{\circ} \mathrm{C}$ is much larger, which is most likely due to uncontrollable agglomeration behaviour and a non-isothermal single particle ${ }^{13)}$. Application of prepolymerization techniques will probably improve the reproducibility at higher temperatures.

All curves show a typical high initial activity, followed by a decline in activity due to deactivation. This decline seems to be higher when the activity is higher. With a Ti-based Ziegler-Natta catalyst, Samson et al. have found similar experimental results for the activity-time curves ${ }^{14)}$.

\section{Model}

It is generally supposed that the reaction rate is first order in the monomer concentration and in the concentration of active centers. This can be described with the following equation:

$$
R_{\mathrm{p}}=k_{\mathrm{p}} C_{\mathrm{m}} C^{*}
$$

In this equation $R_{\mathrm{p}}$ is the polymerization rate (expressed in $\mathrm{kg}$ polymer per $\mathrm{g}$ metallocene per hour), $k_{\mathrm{p}}$ is the propagation constant, $C_{\mathrm{m}}$ the monomer mass concentration at the active center and $C^{*}$ the number of active centers per $\mathrm{g}$ of metallocene. The propagation constant is assumed to be dependent on the temperature according to Arrhenius:

$$
k_{\mathrm{p}}=k_{\mathrm{p}, \infty} \mathrm{e}^{\left(-E_{\mathrm{p}} / R T\right)}
$$

From Fig. 1 it can be seen that the deactivation of the catalyst increases with increasing polymerization rate. The same effect has been found under isothermal 
conditions when the polymerization rate increases with increasing pressure ${ }^{15)}$. We conclude that the rate of monomer insertion itself is the critical step, producing deactivated sites in a statistical way. This leads to Eq. (3) for the rate of change of the number of active sites:

$$
\frac{\mathrm{d} C^{*}}{\mathrm{~d} t}=-k_{\mathrm{d}} R_{\mathrm{p}}
$$

The deactivation constant $k_{\mathrm{d}}$ is a lumped value for all the deactivation reactions. The deactivation constant is assumed to be dependent on the temperature according to Arrhenius, with $E_{\mathrm{d}}$ the deactivation energy:

$$
k_{\mathrm{d}}=k_{\mathrm{d}, \infty} \mathrm{e}^{\left(-E_{\mathrm{d}} / R T\right)}
$$

Under the conditions described above there is no need to implement an activation step. The catalyst is preactivated and shows full activity at the beginning. When the temperature and monomer pressure are constant, the following equation can be found by combining Eq. (1) and Eq. (3):

$$
\frac{\mathrm{d} R_{\mathrm{p}}}{\mathrm{d} t}=-k_{\mathrm{p}} k_{\mathrm{d}} C_{\mathrm{m}} R_{\mathrm{p}}
$$

or

$$
R_{\mathrm{p}}=R_{\mathrm{p} 0} \mathrm{e}^{\left(-k_{\mathrm{p}} k_{\mathrm{d}} C_{\mathrm{m}} t\right)}
$$

with

$$
R_{\mathrm{p} 0}=k_{\mathrm{p}, \infty} \mathrm{e}^{\left(-E_{\mathrm{p}} / R T\right)} C_{0}^{*} C_{\mathrm{m}}
$$

For each temperature, $R_{\mathrm{p} 0}$ and $k_{\mathrm{p}} k_{\mathrm{d}}$ have been determined from the experimental data. In Fig. $2 \mathrm{a}, \ln \left(R_{\mathrm{p} 0} / C_{\mathrm{m}}\right)$ against $1000 / T$ is given to determine the activation energy and $k_{\mathrm{p} \infty} C_{0}^{*}$ according to Eq. (7).
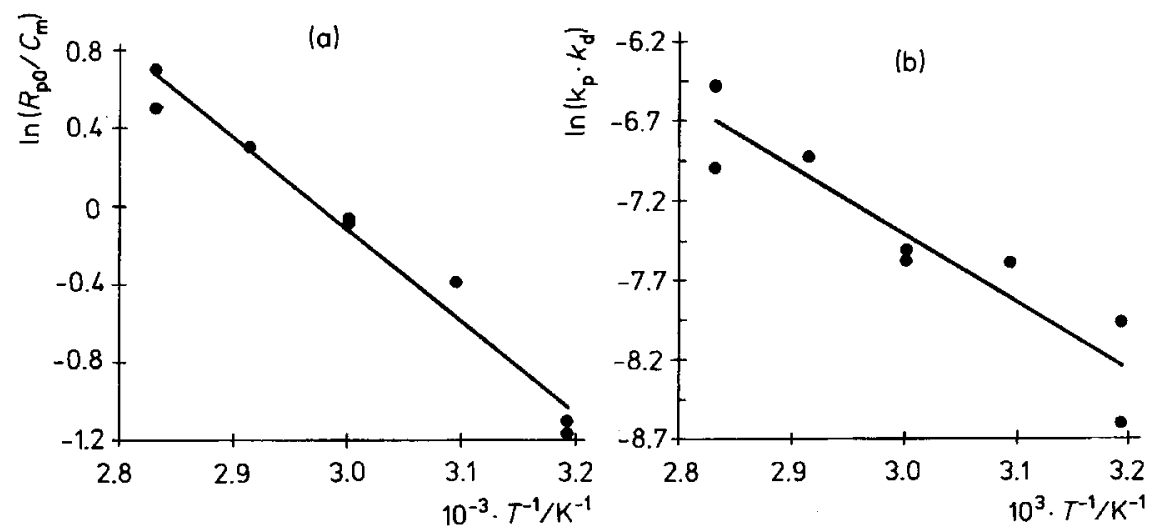

Fig. 2. a) $\ln \left(R_{\mathrm{p} 0} / C_{\mathrm{m}}\right)$ against $1000 / T$ to determine $E_{\mathrm{p}}$ and $k_{\mathrm{pos}} C^{6}$; b) $\ln \left(k_{\mathrm{p}} k_{\mathrm{d}}\right)$ against $1000 / T$ to determine $E_{\mathrm{d}}$ and $k_{\mathrm{p} \infty} k_{\mathrm{d} \infty}$ 
$C_{\mathrm{m}}$ has been taken equal to the mass concentration of the bulk and is calculated with the ideal gas law. In Fig. $2 \mathrm{~b}, \ln \left(k_{\mathrm{p}} k_{\mathrm{d}}\right)$ against $1000 / T$ is given to determine the deactivation energy and $k_{\mathrm{p} 0} k_{\mathrm{d} 0}$.

The determined kinetic constants are:

$$
\begin{array}{ll}
E_{\mathrm{p}}=39.2 \mathrm{~kJ} / \mathrm{mol} & k_{\mathrm{p} \infty} C_{\max }^{*}=1.26 \cdot 10^{6} \mathrm{~m}^{3} /\left(\mathrm{h} \cdot \mathrm{g}_{\mathrm{cat}}\right) \\
E_{\mathrm{d}}=-4.0 \mathrm{~kJ} / \mathrm{mol} & k_{\mathrm{p} \infty} k_{\mathrm{d} \infty}=201 \mathrm{~m}^{3} /(\mathrm{kg} \cdot \mathrm{min})
\end{array}
$$

The negative deactivation energy is physically not possible of course, but can be interpreted as being zero. With our model this indicates that a certain percentage of the monomer insertions (represented by $k_{\mathrm{d}}$ ) leads to deactivated sites independent of temperature. In Fig. 3 the experimental profiles are compared with the modelled profiles. As can be seen from Fig. 3, the fit between model and experimental data is good at temperatures of $70^{\circ} \mathrm{C}$ and lower.

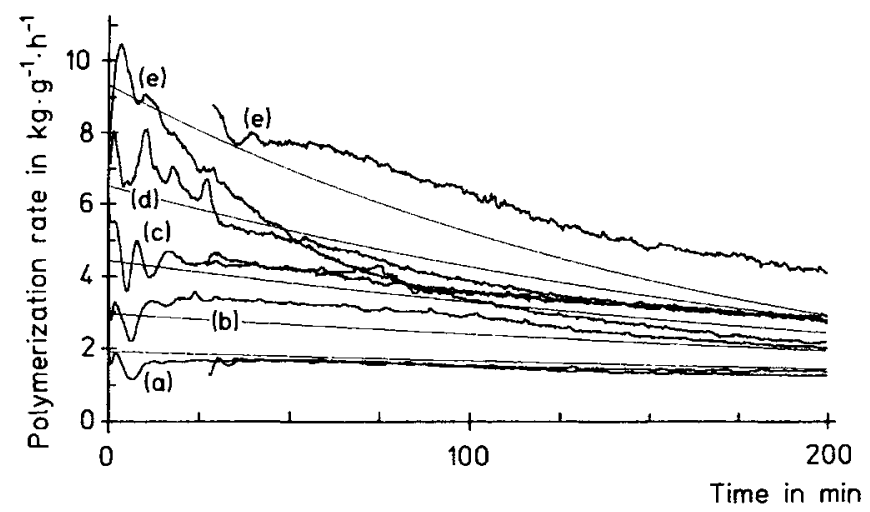

Fig. 3. Experimental and model profiles at different temperatures with $\mathrm{Me}_{2} \mathrm{Si}$ [Ind $]_{2} \mathrm{ZrCl}_{2}$ as catalyst; (a) $40^{\circ} \mathrm{C}$, (b) $50^{\circ} \mathrm{C}$, (c) $60^{\circ} \mathrm{C}$, (d) $70^{\circ} \mathrm{C}$, (e) $80^{\circ} \mathrm{C}$

\section{Conclusions}

We consider the active center of a supported metallocene catalyst as a surfacefixed microreactor which produces polymer independent of other microreactors. Therefore the deactivation of such an active center is not a function of the distance between those centers, the active center concentration. Our kinetic measurements of gas phase polymerization of supported metallocenes lead us to the hypothesis that the deactivation is proportional to the polymerization rate, which can be influenced by a number of physical and chemical factors. From our present data it can be deduced that it is most likely that a certain percentage of the insertions lead to deactivated sites. How this comes about is not clear. It could be the result of a blocking insertion of a monomer molecule or of a complex activation and reactivation mechanism ${ }^{2}$. On the other hand, mechanisms of dilution of reactants by polymer 
formation or local overheating, which are also coupled to polymerization activity, could also play a role. An important indication for the blocked site hypothesis could be the generally noticed increase in activity in the presence of $\mathrm{H}_{2}$ as a chain transfer agent. The small $\mathrm{H}_{2}$ molecule could easily break the bond between blocking polymer and site by chain transfer, reactivating the site in this way. However, this effect has been found only for propylene polymerizations.

\section{List of symbols}

$C^{*} \quad$ number of active centers per gram of metallocene

$C_{\mathrm{m}} \quad$ monomer mass concentration

$E_{\mathrm{p}} \quad$ activation energy

$E_{\mathrm{d}}$ deactivation energy

$k_{\mathrm{p}} \quad$ propagation constant

$k_{\mathrm{d}} \quad$ overall deactivation constant

$R_{\mathrm{p}} \quad$ polymerization rate

$t$ time

$T$ temperature

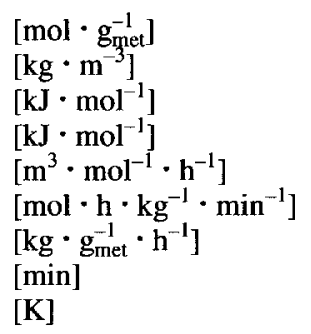

1) V. K. Gupta, S. Satish, I. S. Bhardwaj, J. M. S. - Rev. Macromol. Chem. Phys., C34(3), 439 (1994)

2) H. H. Brintzinger, D. Fischer, R. Mülhaupt, B. Rieger, R. Waymouth, Angew. Chem., Int. Ed. Engl. 34, 1143 (1995)

3) W. Tsai, J. Chien, J. Polym. Sci., Part A: Polym. Chem. 32, 149 (1994)

4) W. Kaminsky, R. Engehausen, K. Zoumis, W. Spaleck, J. Rohrmann, Makromol. Chem. 193, 1643 (1992)

5) B. Rieger, X. Mu, T. Mallin, M. D. Rausch, J. W. Chien, Macromolecules 23, 3559 (1990)

6) S. Jüngling, R. Mülhaupt, U. Stehling, H. Brintzinger, D. Fischer, F. Langhauser, J. Polym. Sci., Part A: Polym. Chem. 33, 1305 (1995)

7) M. Meneghetti, M. Forte, J. Dupont, Polym. Bull. 35, 431 (1995)

8) B. Rieger, C. Janiak, Angew. Makromol. Chem. 215, 35 (1994)

9) B. Liang, Y. Li, G. Xie, Macromol. Rapid Commun. 17, 193 (1996)

10) R. Quijada, J. Dupont, D. Corrêa Silveira, M. Lacerda Miranda, R. Scipioni, Macromol. Rapid Commun. 16, 357 (1995)

11) T. Tsutsui, N. Kashiwa, Polymer 32, 2671 (1991)

12) G. Weickert, P. Roos, G. B. Meier, J. J. C. Samson, K. R. Westerterp, Proc. 4th Meeting Working Party Polymer Reaction Engineering, Thessaloniki (1996)

13) J. J. C. Samson, A. P. H Westenbroek, J. A. M. Kuipers, G. Weickert, K. R. Westerterp, Proc. XIII Int. Conf. Chem. Reac. II, 79 (1996)

14) J. J. C. Samson, G. Weickert, K. R. Westerterp, in preparation

15) P. Roos, G. Weickert, K. R. Westerterp, in preparation 